\title{
The Impact of Natural and Anthropogenic Climate Change on Western North Pacific Tropical Cyclone Tracks*
}

\author{
Angela J. Colbert, Brian J. Soden, And Ben P. Kirtman \\ Rosenstiel School of Marine and Atmospheric Science, University of Miami, Miami, Florida
}

(Manuscript received 2 February 2014, in final form 14 November 2014)

\begin{abstract}
The impact of natural and anthropogenic climate change on tropical cyclone (TC) tracks in the western North Pacific (WNP) is examined using a beta and advection model (BAM) to isolate the influence of changes in the large-scale steering flow from changes in genesis location. The BAM captures many of the observed changes in TC tracks due to El Niño-Southern Oscillation (ENSO), while little change is noted for the Pacific decadal oscillation and all-India monsoon rainfall in either observations or BAM simulations. Analysis with the BAM suggests that the observed shifts in the average track between the phases of ENSO are primarily due to changes in the large-scale steering flow, with changes in genesis location playing a secondary role.

Potential changes in TC tracks over the WNP due to anthropogenic climate change are also assessed. Ensemble mean projections are downscaled from 17 CMIP3 models and 26 CMIP5 models. Statistically significant decreases $[\sim(4 \%-6 \%)]$ in westward moving TCs and increases $[\sim(5 \%-7 \%)]$ in recurving ocean TCs are found. These correspond to projected decreases of 3-5 TCs per decade over the Philippines and increases of 1-3 TCs per decade over the central WNP. The projected changes are primarily caused by a reduction in the easterlies. This slows the storm movement, allowing more time for the beta drift to carry the storm northward and recurve. A previous study found similar results in the North Atlantic. Taken together, these results suggest that a weakening of the mean atmospheric circulation in response to anthropogenic warming will lead to fewer landfalling storms over the North Atlantic and WNP.
\end{abstract}

\section{Introduction}

The western North Pacific (WNP) has the most frequent and most intense tropical cyclones (TCs) of any ocean basin (Yumoto and Matsuura 2001; Ho et al. 2004). Previous studies have shown that natural climate variability influences the frequency, intensity, and tracks of TCs in the WNP (e.g., Chan 2008). More recent studies have suggested that anthropogenic climate change may alter TC tracks in this region through changes in the large-scale steering flow and genesis location (Wu and Wang 2004; Murakami et al. 2011; Yokoi et al. 2013).

\footnotetext{
* Supplemental information related to this paper is available at the Journals Online website: http://dx.doi.org/10.1175/JCLI-D-1400100.s1.

Corresponding author address: Angela J. Colbert, Rosenstiel School of Marine and Atmospheric Science, University of Miami, 4600 Rickenbacker Causeway, Miami, FL 33149.

E-mail: acolbert@rsmas.miami.edu
}

A primary cause of interannual TC variability in the WNP is El Niño-Southern Oscillation (ENSO). A welldocumented influence of ENSO in the WNP is a southeastward displacement in the mean genesis location for TC development during El Niño seasons (Sobel and Maloney 2000; Wang and Chan 2002; Chia and Ropelewski 2002; Camargo et al. 2007). The shift in genesis location increases storm duration, leading to more intense storms, especially during strong El Niño events (Camargo and Sobel 2005).

Previous studies have also noted a shift in TC tracks during ENSO; storms tend to recurve more during El Niño events and less during La Niña events, resulting in a greater threat of landfall during La Niña (Chan 2000; Elsner and Liu 2003; Wu et al. 2004; Yonekura and Hall 2011). When El Niño events are subdivided into central Pacific warming and eastern Pacific warming events, TCs are more likely to recurve during eastern Pacific warming events, resulting in less landfalling TCs (Kim et al. 2011; Wang and Wang 2013).

In addition to ENSO, the Pacific decadal oscillation (PDO) and Asian monsoon can modulate TC activity. 
The PDO is found to influence the decadal variability in $\mathrm{TC}$ intensity and tracks through changes in the largescale circulation (Chan 2008; Liu and Chan 2008). Previous studies have shown the importance of the Asian monsoon for TC activity in the WNP by modulating the frequency of TC genesis within the monsoon trough (Chen et al. 2004, 2006; Wu et al. 2012; Molinari and Vollaro 2013). Strong monsoon rainfall years over India are associated with a greater frequency of monsoon lows and more instability within the monsoon trough (Sikka 1980).

In addition to natural climate variability, the impact of anthropogenic climate change on TC activity is an area of great interest. Many studies have focused on potential changes in TC frequency and intensity (e.g., Oouchi et al. 2006; Stowasser et al. 2007; Knutson et al. 2010; Murakami et al. 2012), with a recent assessment projecting a global reduction of $6 \%-34 \%$ in TC frequency and increase of $2 \%-11 \%$ in TC intensity (Knutson et al. 2010; Yu et al. 2010).

Additional studies have considered the potential impact of anthropogenic climate change on TC tracks. $\mathrm{Wu}$ and Wang (2004) identified the two main contributors to TC track changes in the WNP as variations in the largescale steering flow and genesis location. Their results projected a shift to northeastern recurving TCs by the midcentury. Murakami et al. (2011) and Yokoi et al. (2013) found similar results with an increase in recurving storms and decrease in straight-moving (westward) storms. They found a projected reduction in TC frequency in the region, but attribute the increase in central WNP TC tracks to an eastward shift of genesis and secondly to changes in the large-scale steering flow that favor recurvature.

We follow the methodologies established in Colbert and Soden (2012, hereafter CS12) and Colbert et al. (2013, hereafter CSVK13) to examine the impact of natural and anthropogenic climate variability on TC tracks in the WNP. First we examine the influence of large-scale steering flow and genesis location on the observed climatology (section 2). We show that the difference between straight-moving and recurving storms is primarily attributable to a more southerly genesis location for the former, rather than a difference in steering flow. However, for storms that do recurve, the steering flow plays a key role in determining whether they threaten land or recurve into the open ocean. Next we analyze the influence of natural climate variations on TC tracks and find modest influence of ENSO on TC tracks (section 3). These are determined to primarily result from changes in the large-scale steering flow. Lastly we consider the impact of anthropogenic climate change on TC tracks (section 4). Using coupled ocean-atmosphere model projections of the changes in steering flow and genesis parameters, we find a significant decrease in westward moving TCs and an increase in recurving TCs. The projected changes are primarily caused by a reduction in the easterlies that allow more time for the storm to drift northward and recurve.

\section{Control climatology}

\section{a. TC track classification}

To establish an observational TC track climatology, the International Best Track Archive for Climate Stewardship (IBTrACS) database is used (Knapp et al. 2010). This database averages best track position observations for every $6 \mathrm{~h}$ from multiple agencies in the WNP [see Knapp et al. (2010) for more details]. We limit our study region to tracks that form in the main development region (MDR), defined as $5^{\circ}-20^{\circ} \mathrm{N}, 135^{\circ} \mathrm{E}-$ $180^{\circ}$ (Fig. 1), for the period 1976-2010. This period is believed to provide a more accurate climatology as it corresponds to the beginning of the satellite era for identifying and tracking TCs. As in CS12, we focus on MDR forming TCs to examine the influence of changes in the large-scale steering flow on TC tracks. However, we recognize that numerous TCs form outside our region of interest (e.g., South China Sea and Philippines Sea) but exclude these because of their proximity to land and the defined track classification boundaries (Fig. 1a).

To examine the impact of climate variability and establish a base climatology for comparison, we divide TC tracks into three categories: straight moving (SM), recurving landfall (RCL), and recurving ocean (RCO). SM tracks threaten the Philippines and southern China. RCL tracks threaten Taiwan, northern China, the Korean peninsula, and Japan, and RCO tracks recurve into the open ocean without threatening land. Each is classified based on the track category boundary that it passes through first (Fig. 1b). A similar track classification was used in Elsner and Liu (2003). Storms that dissipate before reaching any of the track category boundaries are classified based on their dissipation location: storms that dissipate west of $145^{\circ} \mathrm{E}$ and south of $20^{\circ} \mathrm{N}$ are classified as SM, storms that dissipate west of $135^{\circ} \mathrm{E}$ and north of $20^{\circ} \mathrm{N}$ or west of $145^{\circ} \mathrm{E}$ and north of $25^{\circ} \mathrm{N}$ are classified as $\mathrm{RCL}$, and storms that dissipate east of $145^{\circ} \mathrm{E}$ and north of $20^{\circ} \mathrm{N}$ are classified as RCO. If a given TC is still not grouped in a track category classification, then the mean angle of trajectory computed over the lifetime of the storm is used to extrapolate the storm into one of the track category boundaries. For the 428 TCs included in the study, this categorization yields 149 SM TCs, 185 RCL TCs, and 94 RCO TCs. This track classification will be used throughout the study to analyze TC track 

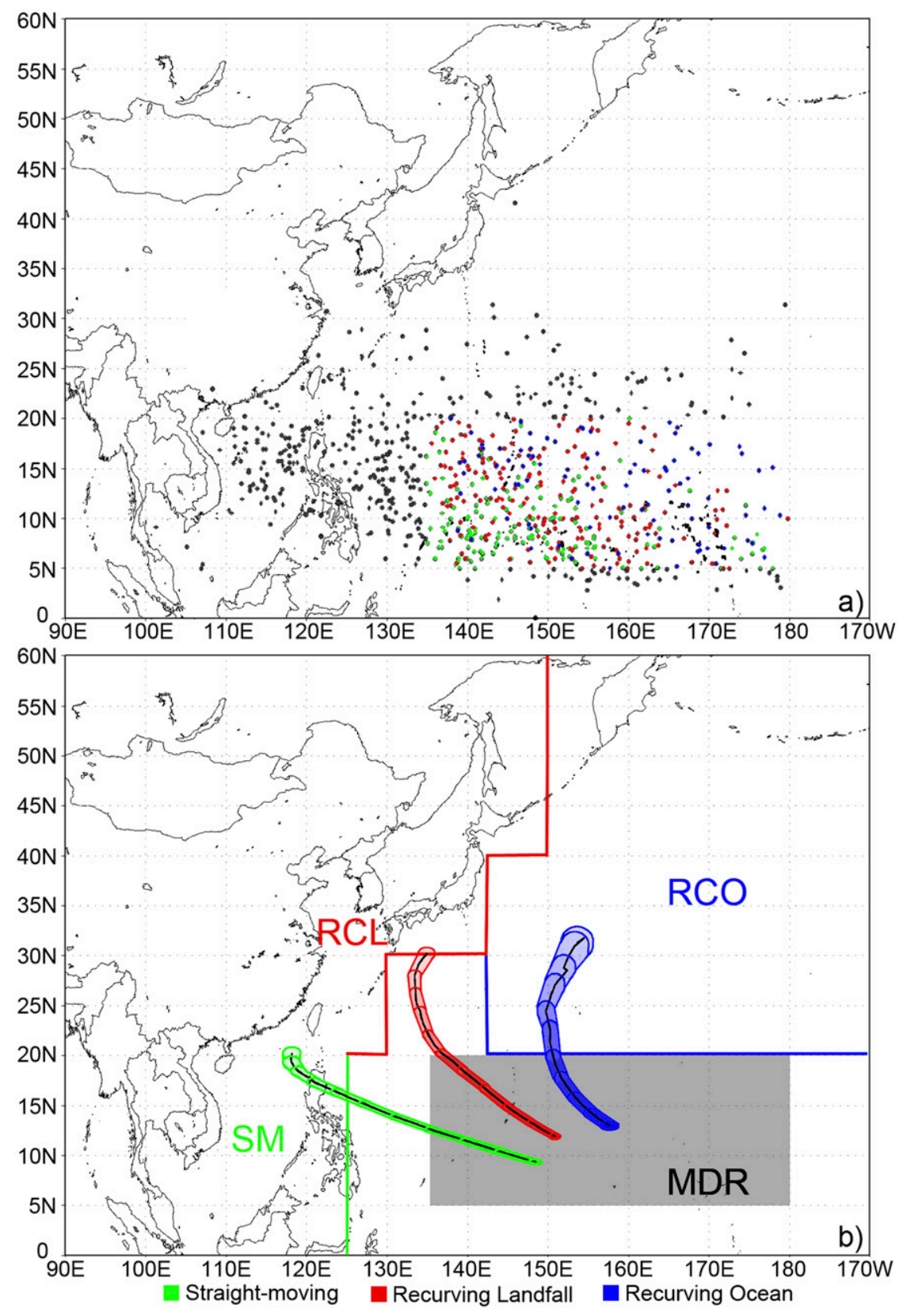

FIG. 1. (a) The genesis location of all TCs in the WNP from 1976 to 2010, where green are straight-moving (SM), red are recurving landfall (RCL), and blue are recurving ocean (RCO) TCs that form in the main development region (MDR); gray are TCs that form outside of the MDR, many of which are excluded due to their close proximity to land. (b) The average tracks and track classification boundaries for the three track categories based on the region of threat. The black line denotes the average track where the surrounding ellipses are \pm 1 standard error. The gray box defines the boundaries of the MDR.

frequency and its dependence upon different modes of climate variability.

Figure $1 \mathrm{~b}$ shows the average 10-day TC track for each of the three categories. The shaded cone represents \pm 1 standard error in longitude and latitude associated with the tracks. Overall, the classification system successfully produces three distinct track types based on the predefined regions of threat.

To determine the probability of obtaining a given track type based on genesis location, we examine the 

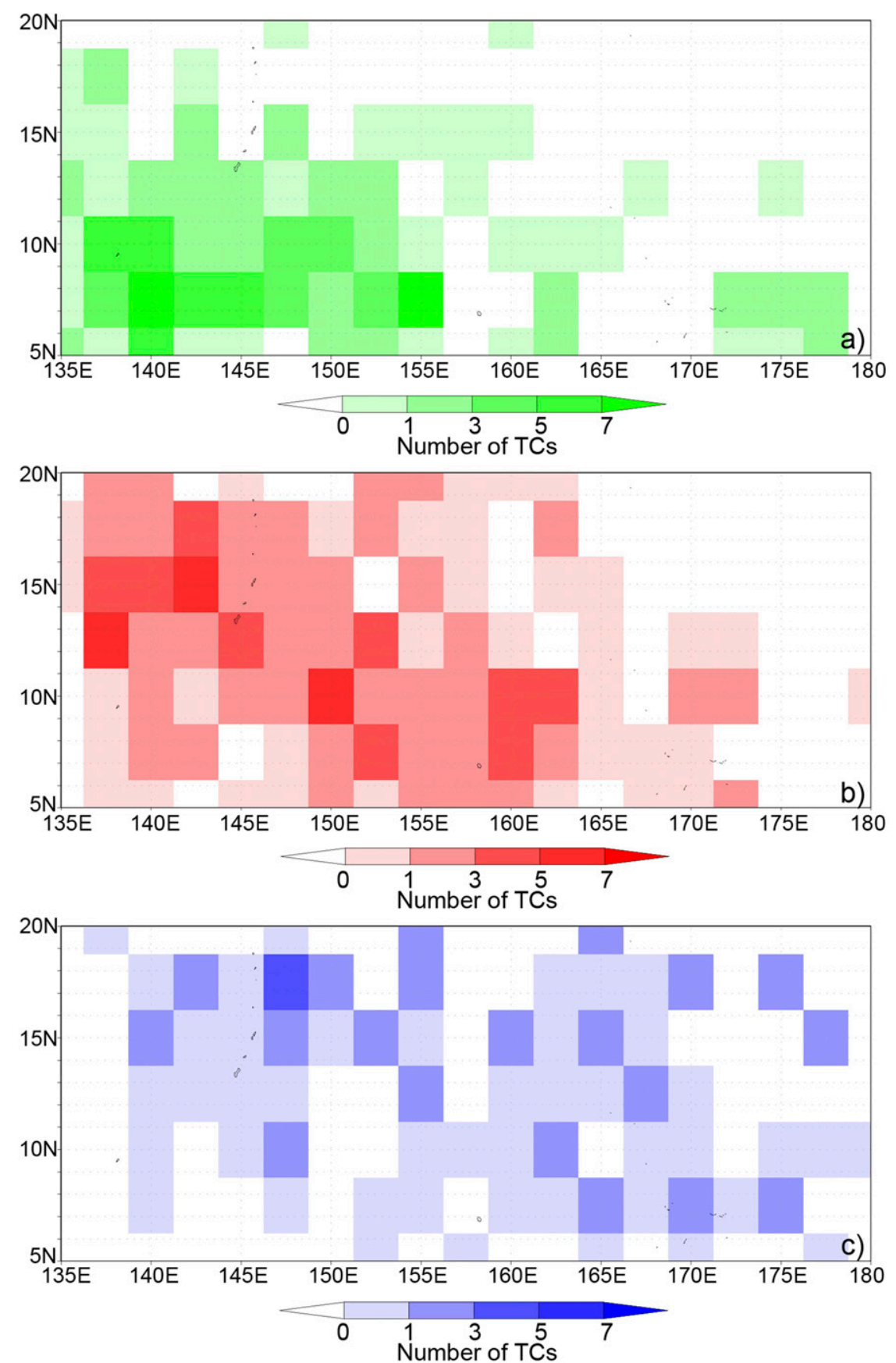

FIG. 2. The gridded distribution of genesis location within the MDR for (a) SM, (b) RCL, and (c) RCO TCs. The values represent the number of TCs that formed in each $2.5^{\circ}$ grid box during the period 1976-2010.

spatial distribution of genesis for the three track categories (Fig. 2). Similar to the North Atlantic (CS12), SM TCs are more likely to form farther south in the MDR than any other track type, whereas RCO TCs are more likely to form in the north and east MDR. RCL TCs were much less likely to form in the eastern MDR, with a majority forming in a diagonal region from the south central to northwest MDR. All of these distributions are expected as the farther north and east a TC forms, the less time is available for the $\beta$ drift to steer the storm out of the easterlies so that it may recurve. The farther west the TC forms, the more likely the storm is to make landfall. 

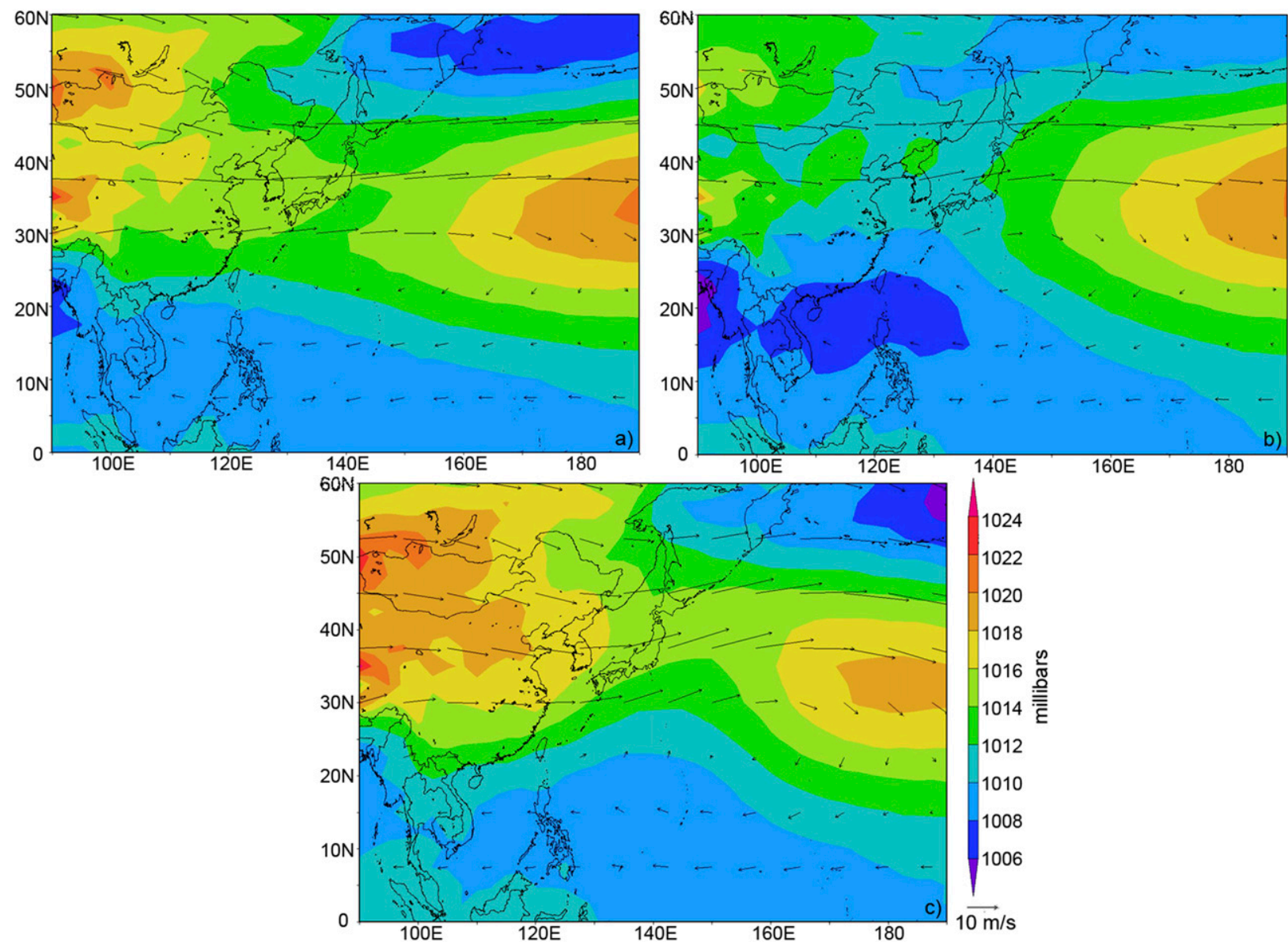

FIG. 3. The average SLP and deep-layer steering flow (black arrows) for all TCs classified as (a) SM, (b) RCL, and (c) RCO.

\section{b. Characterization of the large-scale steering environment}

Using the best-track position estimate from IBTrACS, the 6-hourly TC vortex is located and removed from the corresponding sea level pressure (SLP) and horizontal wind fields $(850,500$, and $200 \mathrm{mb} 1 \mathrm{mb}=1 \mathrm{hPa})$ in the National Centers for Environmental Prediction (NCEP)National Center for Atmospheric Research (NCAR) reanalysis data (Kalnay et al. 1996) as done in CS12 (see the appendix in CS12 for more details). These modified SLP and horizontal wind fields are used to calculate composites that show the dominant large-scale steering flow for each track category. For the wind, a deep-layer steering flow $\mathbf{V}$ is computed from the horizontal wind fields at 850 , 500 , and $200 \mathrm{mb}$, defined as $\mathbf{V}=0.25 \mathbf{V}_{850 \mathrm{mb}}+0.5 \mathbf{V}_{500 \mathrm{mb}}+$ $0.25 \mathbf{V}_{200 \mathrm{mb}}$. To compute the SLP and wind field composites, the average is taken of every corresponding 6-h field when a TC is present for a given track category.

Figure 3 depicts the average SLP and deep-layer steering flow for the three track categories. As expected, the center of the anticyclonic circulation in the deep-layer steering flow shifts from $120^{\circ} \mathrm{E}$ for $\mathrm{SM}$ storms to $150^{\circ} \mathrm{E}$ for RCO storms, corresponding to a weakening of the SLP in the western part of the basin, which results from a reduction in the western extension of the North Pacific subtropical high. As the underlying latitudinal distribution of the steering flow is similar (e.g., easterlies in the tropics), it is the longitudinal location of the southerlies that is related to a shift in the SLP.

To remove any potential for seasonal bias in the results, an anomaly field is calculated for the SLP and deep-layer steering flow for each time when a TC is present. To calculate the anomaly field, first a climatological field is computed as the 35 -yr climatological mean at each 6-hourly time resolution for SLP and the deep-layer steering flow. Then the climatological field is subtracted from the original SLP and deep-layer steering flow fields for every time a TC is present. The anomalous SLP and deep-layer steering flow for the three track categories is then composited and shown in Fig. 4. Similar to the North Atlantic (CS12), each track category exhibits an area of anomalous low pressure along the path that the TCs follow (e.g., over the Philippines 


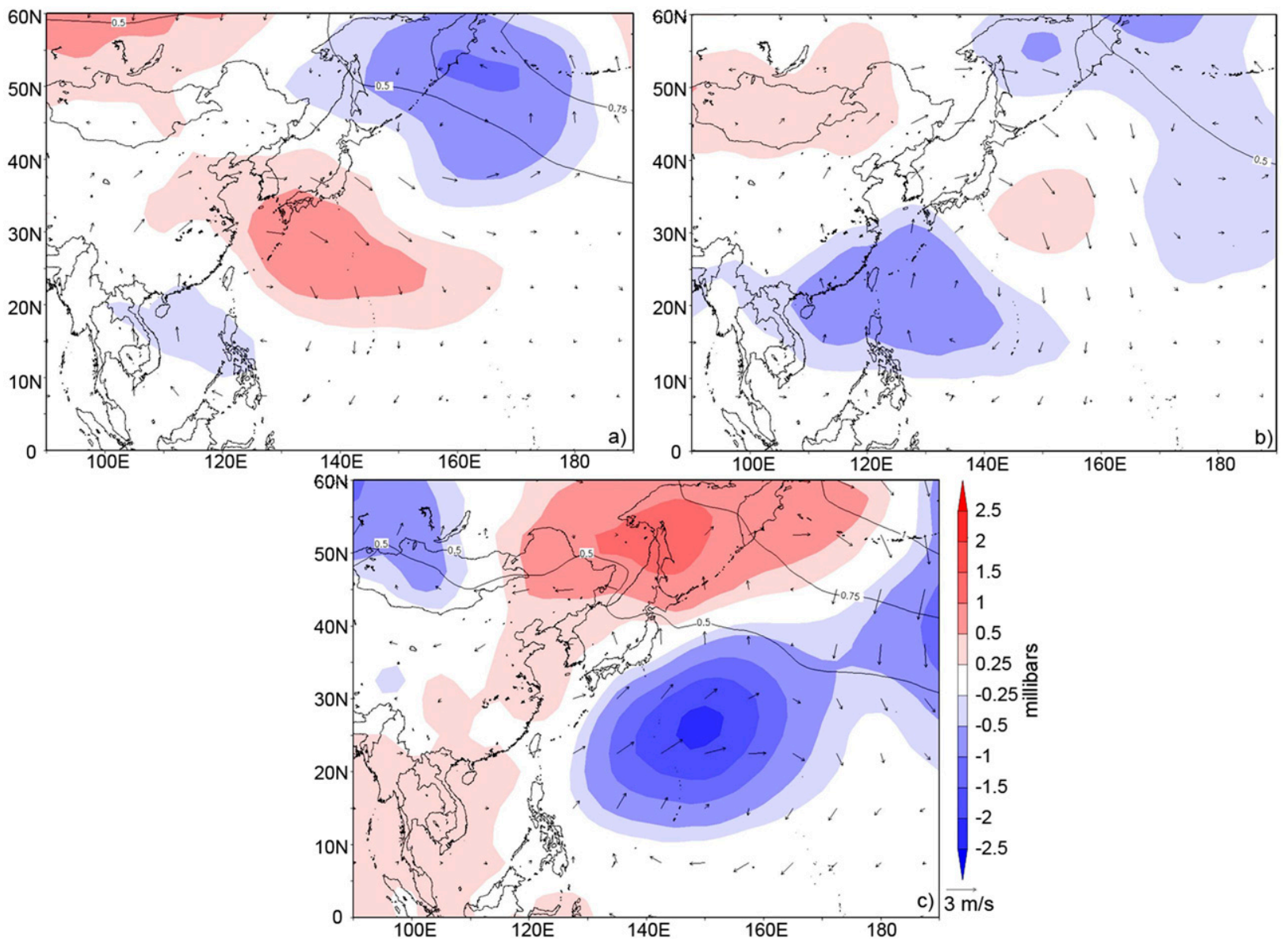

FIG. 4. The average SLP and deep-layer steering flow (black arrows) for TCs classified as (a) SM, (b) RCL, and (c) RCO relative to the 35-yr climatological mean. The black contours denote the standard errors for SLP at 0.5, 0.75, and $1 \mathrm{mb}$.

and South China Sea for SM TCs). As in Fig. 3, the SLP anomalies correspond to anomalous anticyclonic circulation that shifts eastward with track type (from SM to RCO). The resultant anomalous anticyclonic circulation has a steering flow that steer TCs toward an anomalous area of lower SLP and away from an anomalous area of higher SLP.

Figure 5 compares the anomalous SLP and deep-layer steering flow for each track category. Figure 5a (SM$\mathrm{RCO}$ ) indicates that SM storms experience enhanced SLP across the central WNP corresponding to anomalous northerlies that inhibit recurvature in the central WNP and favor a southward track for the storm. These northerlies are part of an anomalous anticyclonic circulation that steers TCs toward the Philippines rather than the open ocean. Similarly, Fig. 5b (SM-RCL) indicates that SM storms are associated with enhanced SLP across Taiwan and southern Japan relative to RCL storms that correspond to anomalous northerlies in the deep-layer steering flow. Anchored by the anomalous northerlies, an anomalous anticyclonic circulation develops that steers
TCs away from the coastlines of Taiwan, China, and Japan and toward the Philippines. Lastly, Fig. 5c (RCL$\mathrm{RCO}$ ) indicates that RCL storms experience enhanced SLP centered near $150^{\circ} \mathrm{E}$ with weakened SLP over Taiwan and eastern China. As with the other differences, the enhanced SLP is associated with anomalous northerlies resulting in an anomalous anticyclonic circulation centered at $130^{\circ} \mathrm{E}$ that steers TCs toward Taiwan and China, and away from the open ocean.

\section{c. Beta and advection model}

To analyze the relative influence of natural and anthropogenic climate variability on TC track changes due to changes in the large-scale steering flow and genesis location, the beta and advection model (BAM) from CS12 is used to help analyze the climatology of WNP TC tracks for the period 1976-2010. The BAM uses the deep-layer steering flow computed from the corresponding 6-hourly NCEP-NCAR reanalysis data and an empirically fitted $\beta$ drift. There are two parameters that can be adjusted for the $\beta$-drift component: the $\beta$ speed and the $\beta$ angle. A range of 


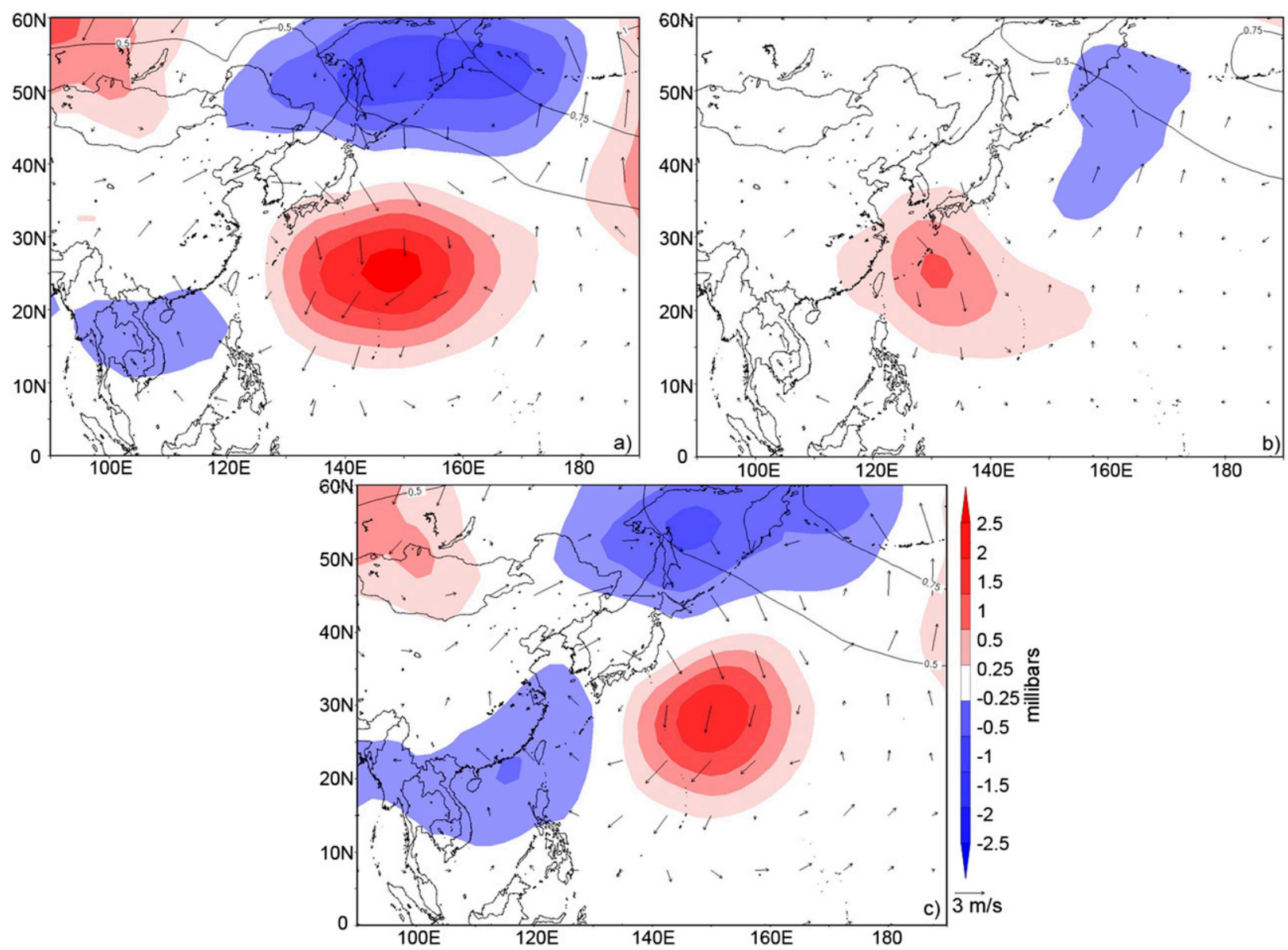

FIG. 5. The difference in SLP and the deep-layer steering flow (black arrows) from the anomaly fields in Fig. 4 for (a) SM-RCO, (b) SM-RCL, and (c) RCL-RCO. The black contours denote the standard error of the SLP at 0.5, 0.75, and $1 \mathrm{mb}$.

values of the maximum $\beta$ speed and angle was tested. To determine the best fit, half of the tracks were randomly chosen and the sum of the distance error between the observed tracks and simulated tracks was calculated. This was repeated with the other half of the tracks, and the parameters with the lowest error were chosen. The best fit was found for a $\beta$ speed that varied between 1.5 and $2.75 \mathrm{~m} \mathrm{~s}^{-1}$ based on the TC's current angle of trajectory, as in CS12, and a $\beta$ angle held constant at $310^{\circ}$. Additional sensitivity analyses were conducted that altered the proportions of the deep-layer steering flow between the upper-level and lower-level winds to determine the viability of the deep-layer steering flow for simulating TC tracks in the WNP. Various weights were applied that reduced the upper-level winds and increased the lower-level winds in 0.05 increments; however, they resulted in larger simulated track errors than the chosen deep-layer steering flow. Thus, the deeplayer steering flow as defined in section $2 b$ is used.

Figure 6 shows the resulting storm density plot for the observed TC tracks (Fig. 6a) compared to the BAM simulated TC tracks (CTRL tracks; Fig. 6b). Each track is initialized at the historical genesis location and run for the historical storm lifetime for all 428 TCs included in the study. The storm density is calculated as the total number of TCs that travel through a $5^{\circ} \times 5^{\circ}$ grid box over the 35-yr period. A given TC is counted only once per grid box, then divided by the total number of seasons. The BAM simulated storm density exhibits greater spatial variability with biases to the southwest and northeast of the observed distribution.

To evaluate the fit of the BAM we compare the average tracks for each of the three categories for observations and the CTRL simulations (Fig. 7a). It is clear that the error in the BAM simulated tracks increases substantially after about 7 days, with SM and RCL tracks recurving more sharply than in observations. However, the decrease in model skill after 7 days is due in part to fewer TCs being present (i.e., many storms have dissipated). Despite the simplified nature of the model, it does successfully capture the three distinct track categories. 


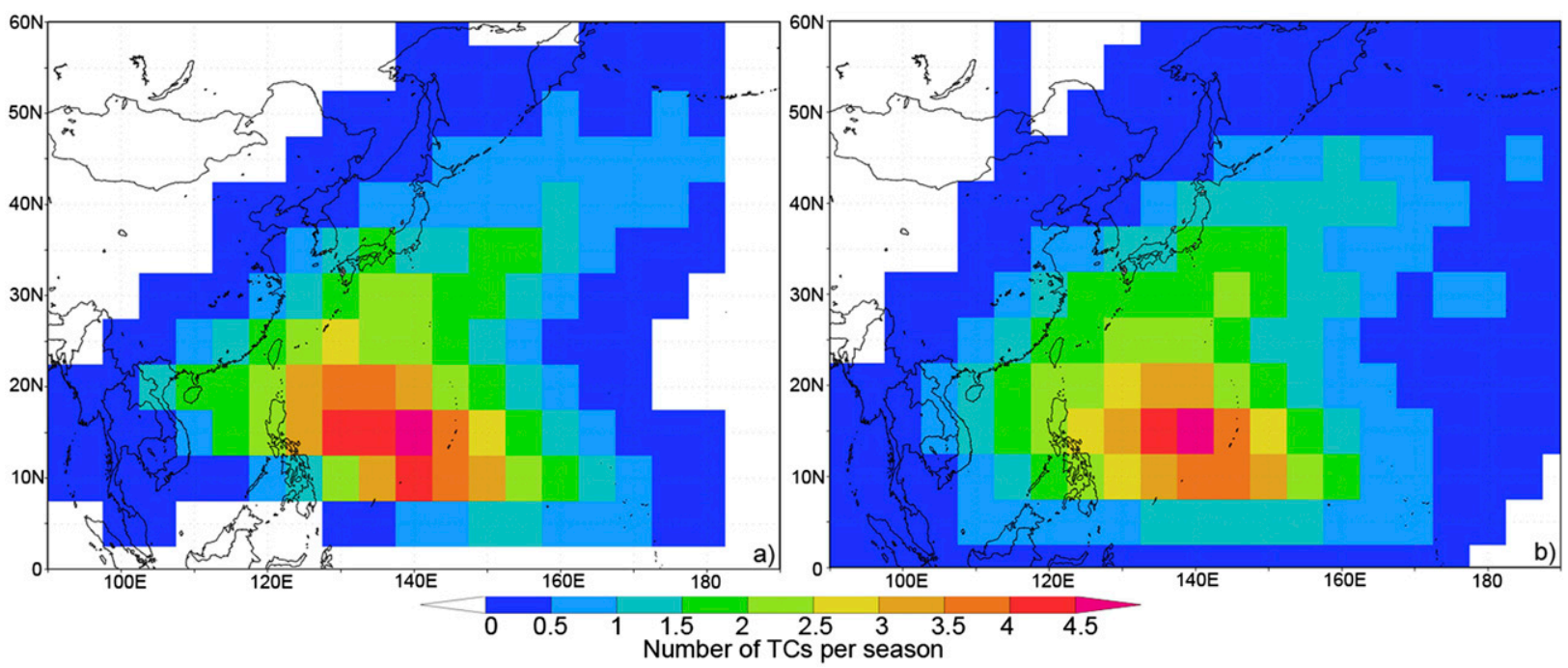

FIG. 6. The spatial distribution of storm counts for all 428 TCs for the period 1976-2010 from (a) observations and (b) the BAM CTRL simulations using NCEP winds and observed genesis locations. The value in each $5^{\circ} \times 5^{\circ}$ grid box corresponds to the number of TCs per season.

One advantage of the BAM is the ability to separate the influences of the large-scale steering flow from genesis location. We accomplish this by uniformly seeding the MDR, rather than using the observed genesis location. Each TC is initialized at the same historical time as observed, but tracks are simulated for genesis at every $2.5^{\circ}$ grid box in the MDR and then advected for 10 days. We then average the tracks based on their original TC track classification (i.e., how they were classified using the observed genesis location). Figure $7 \mathrm{~b}$ shows the average of the uniformly seeded tracks. When the effects of genesis location are removed, SM TCs follow a similar track to RCL TCs, suggesting that the more southern genesis location of SM TCs is an important factor in determining their westward tracks. However, the RCL and RCO average tracks are very different from each other, suggesting that differences in the large-scale steering flow are an important factor in their track differences. These results are similar to those found in the North Atlantic (CS12).

\section{Natural climate variability}

Analyzing natural climate variability provides insight into the relative sensitivity of the region to climate variations and a basis for testing the ability of the BAM to capture observed climate variability. In this section, we examine the influence of ENSO, PDO, and the allIndia monsoon rainfall (IMR) on TC tracks. The TCs are categorized according to the phase of the climate anomaly. Their corresponding SLP fields and average tracks are then calculated. Following CS12, a two-tailed binomial test is conducted on the TC track frequencies to determine statistical significance and a standard error analysis (with a temporal autocorrelation taken into account) is conducted on the SLP fields.

\section{a. El Niño-Southern Oscillation}

For ENSO, we classify each season from 1976-2010 as either El Niño, La Niña, or neutral based on the Climate Prediction Center's oceanic Niño index classification (Climate Prediction Center 2011). This index defines an El Niño event as five consecutive months in which the 3-month running mean Niño-3.4 index is greater than $0.5^{\circ} \mathrm{C}$ (or less than $-0.5^{\circ} \mathrm{C}$ for a La Niña event). Each season is classified using the phase of the NovemberJanuary 3-month mean, where November and December are from the same year as the season being classified. For the period 1976-2010, this results in 12 El Niño, 8 La Niña, and 15 neutral seasons.

There is a slight increase in TC frequency in the MDR during El Niño seasons with an average of 13.8 storms per season, and a decrease in TCs during La Niña seasons with an average of 8.75 storms per season. The average TC frequency for the entire dataset is 12.2 storms per season. The increase in TC frequency in the MDR during El Niño is most likely related to the southeastward shift in TC genesis toward the MDR, rather than a basinwide signal, which shows a slight decrease in TC frequency during El Niño (Yonekura and Hall 2011; Zhan et al. 2011; Tao et al. 2012).

Figure 8a shows the TC track frequencies during the three phases of ENSO. There is a shift toward recurving TCs during El Niño seasons and increase in land threatening TCs (SM and RCL) during La Niña seasons. These shifts are consistent with that found in previous studies (e.g., Wu et al. 2004); however, none of the shifts 

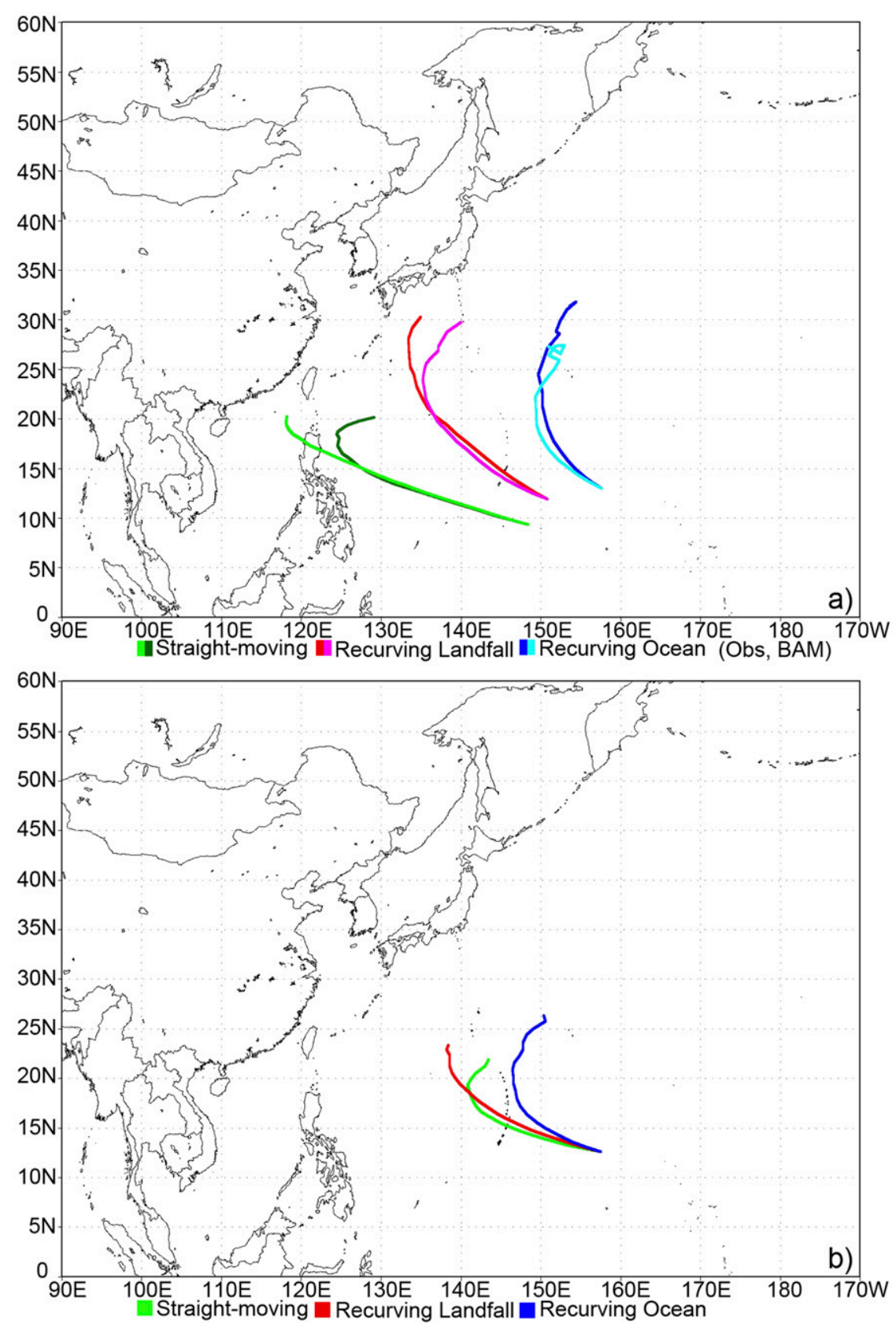

FIG. 7. (a) The average track for each track category (SM, RCL, and RCO) from observations and BAM simulations. (b) The average tracks for each track category from BAM simulations when the MDR is uniformly seeded.

is statistically significant based upon a two-tailed binomial test (see CS12).

Figure $8 \mathrm{~b}$ shows the difference in SLP and deep-layer steering flow anomalies between El Niño and La Niña seasons. The averages are calculated by compositing the fields for each TC according to its ENSO phase. During El Niño, there is a reduction in the SLP along the northern half of the MDR and an increase along the coastline. This corresponds to an anomalous steering flow that favors recurvature by steering TCs away from the coastline and toward the open ocean. As expected, the average El Niño track is farther east than the La Niña track, which is associated with a southeastward shift in the mean genesis location during El Niño.

Figure 8c shows the ENSO composites of the BAM simulations when the model is seeded using the observed 

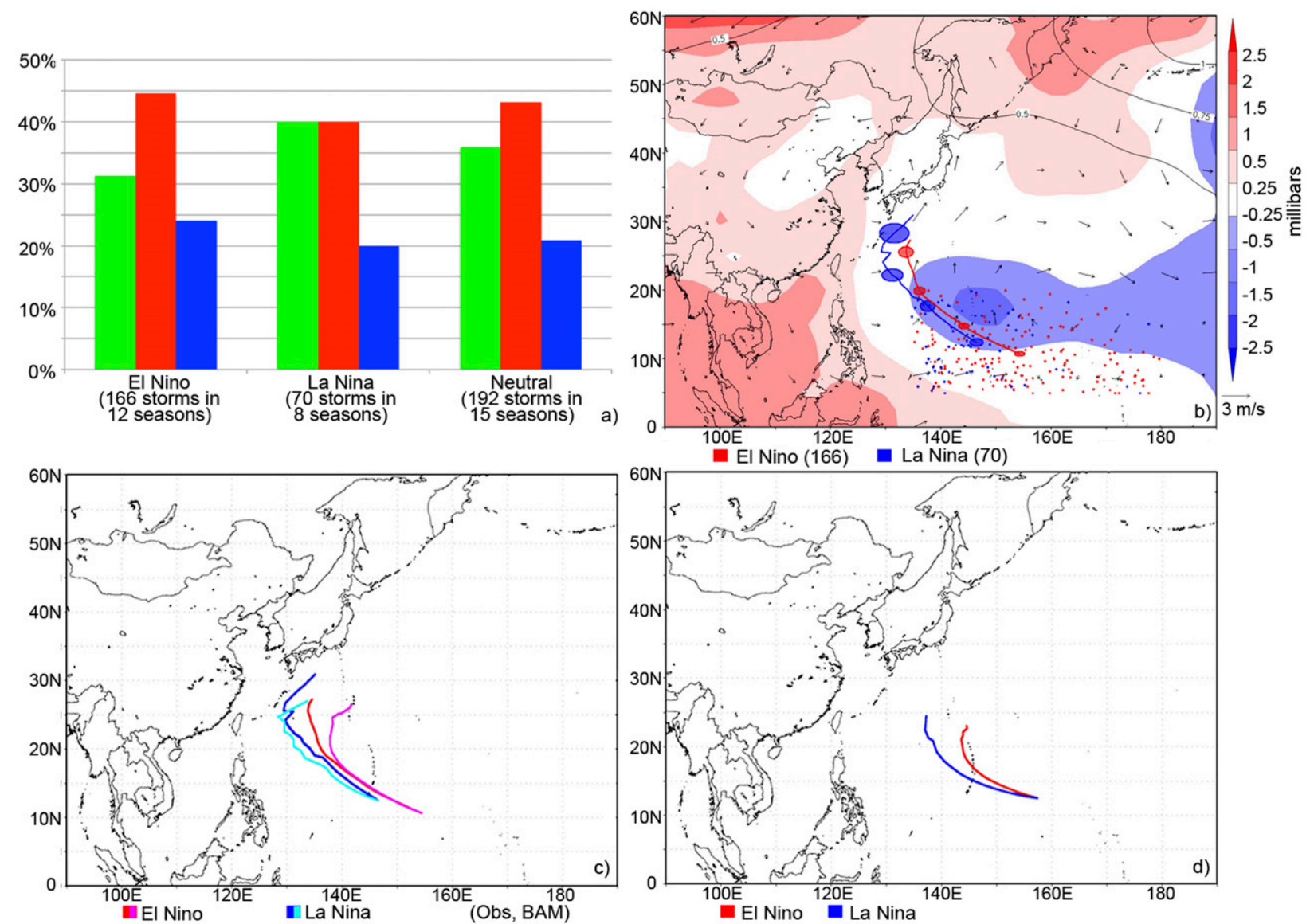

FIG. 8. (a) The frequency distribution for each track type as a function of the phase of ENSO. Green is for SM, red is for RCL, and blue is for RCO tracks. The value in parentheses indicates the number of TCs included in the frequency distribution for each phase. (b) The difference in the average SLP and deep-layer steering flow (black arrows) for El Niño minus La Niña relative to the 35-yr climatology mean. The black contours denote the standard error for SLP at $0.5,0.75$, and $1 \mathrm{mb}$. The two plotted tracks are the 10-day average track for all TCs included in a given classification, with the ellipses being \pm 1 standard error for $0,3,6$, and 9 days, respectively. The points show the corresponding genesis locations for each TC included in a given phase classification. (c) The average track of all TCs as a function of the phase of ENSO for observations and BAM simulations using observed genesis locations. (d) The averaged TC tracks for BAM simulations generated by a uniform seeding of the MDR.

genesis locations. Despite an eastward bias in the model tracks after about 7 days, the model does capture the shift in the average tracks between El Niño and La Niña. The composites of the uniform seeding experiments (Fig. 8d) also capture this shift in track, suggesting that changes in steering flow play a key role in enhancing the frequency of recurving storms during El Niño and not just the southeastward shift in genesis.

\section{b. Pacific decadal oscillation and all-India monsoon rainfall}

The PDO index is calculated as the leading PC of the monthly sea surface temperature (SST) anomalies poleward of $20^{\circ} \mathrm{N}$ in the North Pacific with the monthly mean global average SST anomalies removed (Mantua et al. 1997). TCs are classified as positive or negative phase based on the phase of the PDO index during the corresponding month of genesis for the given TC. This classification results in 293 storms during the positive phase and 135 storms during the negative phase.

For the IMR, a TC season is classified as positive or negative based on the phase of the all-India monsoon rainfall index (Parthasarathy et al. 1995). The index is calculated as the anomaly of rainfall during the months of June-September. This results in 21 positive seasons (above average rainfall) and 14 negative seasons (below average rainfall).

The analysis for both PDO and IMR found no significant changes in TC tracks.

\section{Anthropogenic climate change}

To study the impact of anthropogenic climate change on TC tracks, we adapt the methodology established in 

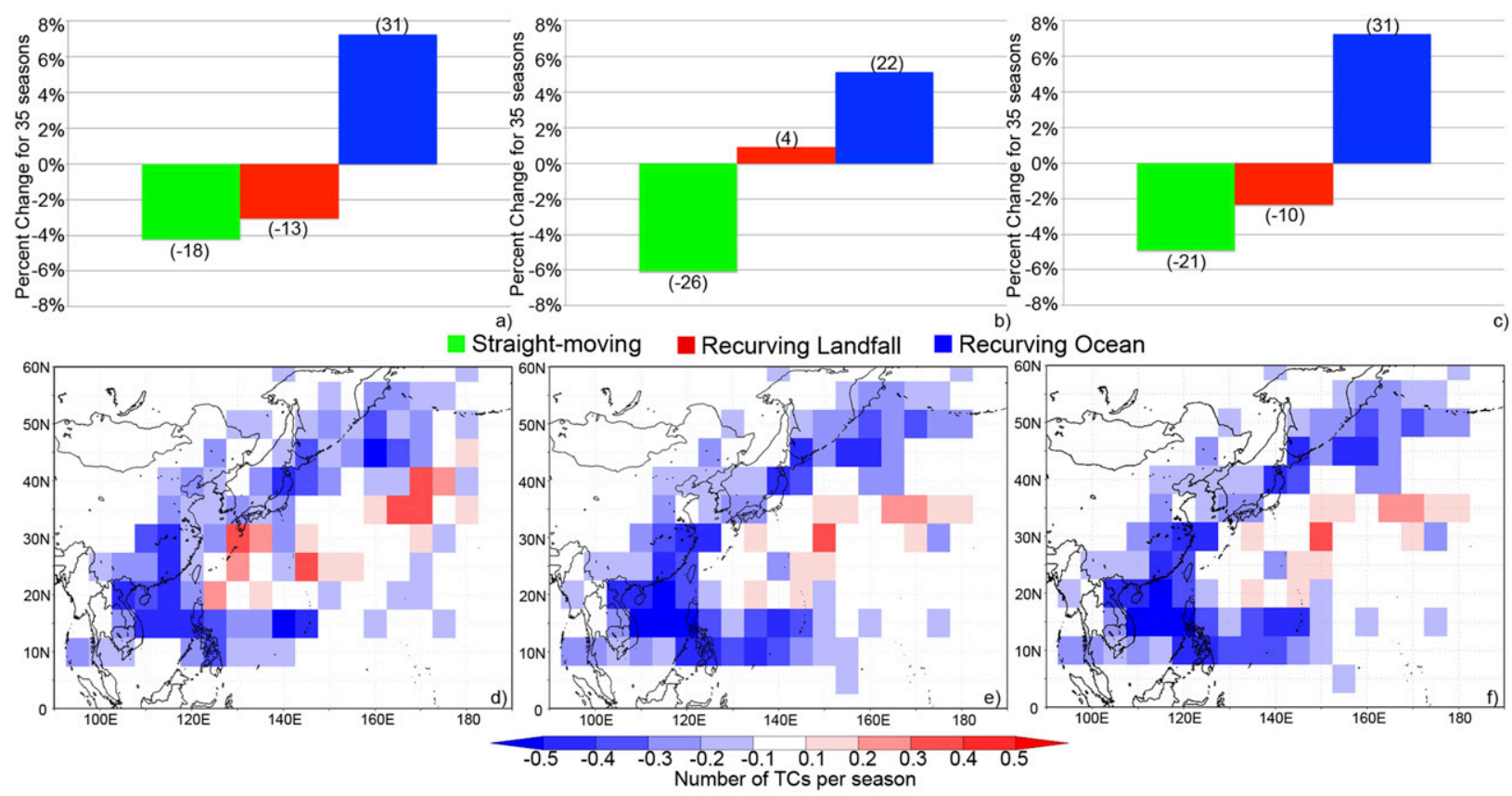

FIG. 9. (top) The projected changes in frequency of the three track types and (bottom) the spatial distribution of TC storm count between the CTRL and climate change simulations for the (a),(d) CMIP3 experiment using GPI ${ }_{\mathrm{EN}}$, (b),(e) CMIP5 experiment using $\mathrm{GPI}_{\mathrm{EN}}$, and (c),(f) CMIP5 experiment using $\mathrm{GPI}_{T}$. The numbers in parentheses in (a)-(c) represent the change in the number of storms within each track category.

CSVK13. The BAM simulations described in section 2c are used as the control simulations (CTRL tracks) for this portion of the study. Projections of the changes in large-scale steering flow and TC genesis parameters are obtained from two coordinated experiments of coupled ocean-atmosphere model simulations. Specifically, we use the A1b scenario for 17 models from the Coupled Model Intercomparison Project (CMIP) phase 3 (CMIP3) and the $1 \%$ annual increase in $\mathrm{CO}_{2}$ to quadrupling scenario (1pctCO2) for 26 models from CMIP phase 5 (CMIP5). The A1b simulation from CMIP3 provides a more realistic projection of the potential radiative forcing to be experienced over the twenty-first century that includes both greenhouse gases and aerosols, whereas the 1 pctCO 2 provides an idealized scenario using only $\mathrm{CO}_{2}$ changes but with larger radiative forcing. These experiments will be referred to as CMIP3 and CMIP5, respectively. The CMIP3 experiment also allows for a direct comparison with a similar analysis in the Atlantic by CSVK13, who also used the A1b scenario. Tables S1 and S2 in the supplemental material provide a list of the models used for each experiment.

To examine the impact of anthropogenic climate change on the large-scale steering flow, the monthly horizontal wind anomalies for the deep-layer steering flow (comprising the 850-, 500-, and 200-mb levels) are computed for each of the models. For the CMIP3 experiment, the anomalies are calculated as the difference between the 20-yr average at the beginning and end of the twenty-first century [(2081-2100) - (2001-20)]. Similarly for the CMIP5 experiment, the anomalies are calculated as the difference between the 20-yr average at the beginning and end of 140 years of the simulation [(years 121-140) - (years 1-20)]. Following CSVK13, these anomalies are added to the corresponding NCEP-NCAR reanalysis wind fields and linearly interpolated to match the 6-hourly time resolution. The BAM model is then run for all 428 TCs used in the CTRL simulation. The multimodel ensemble mean is then calculated for each experiment (CMIP3 and CMIP5). Although there may be potential contributions to the anomalous circulation from changes in localized circulations, due to TC size or other factors, these are not included in this study as the focus is on changes in the large-scale circulation only.

To examine the impact of anthropogenic climate change on genesis, two versions of a genesis potential index (GPI) are used. We use the Emanuel and Nolan (2004) GPI (referred to as $\mathrm{GPI}_{\mathrm{EN}}$ ), which is defined as

$$
\mathrm{GPI}_{\mathrm{EN}}=\left|10^{5} \eta\right|^{3 / 2}\left(\frac{\mathcal{H}}{50}\right)^{3}\left(\frac{V_{\text {pot }}}{70}\right)^{3}\left(1+0.1 V_{\text {shear }}\right)^{-2}
$$



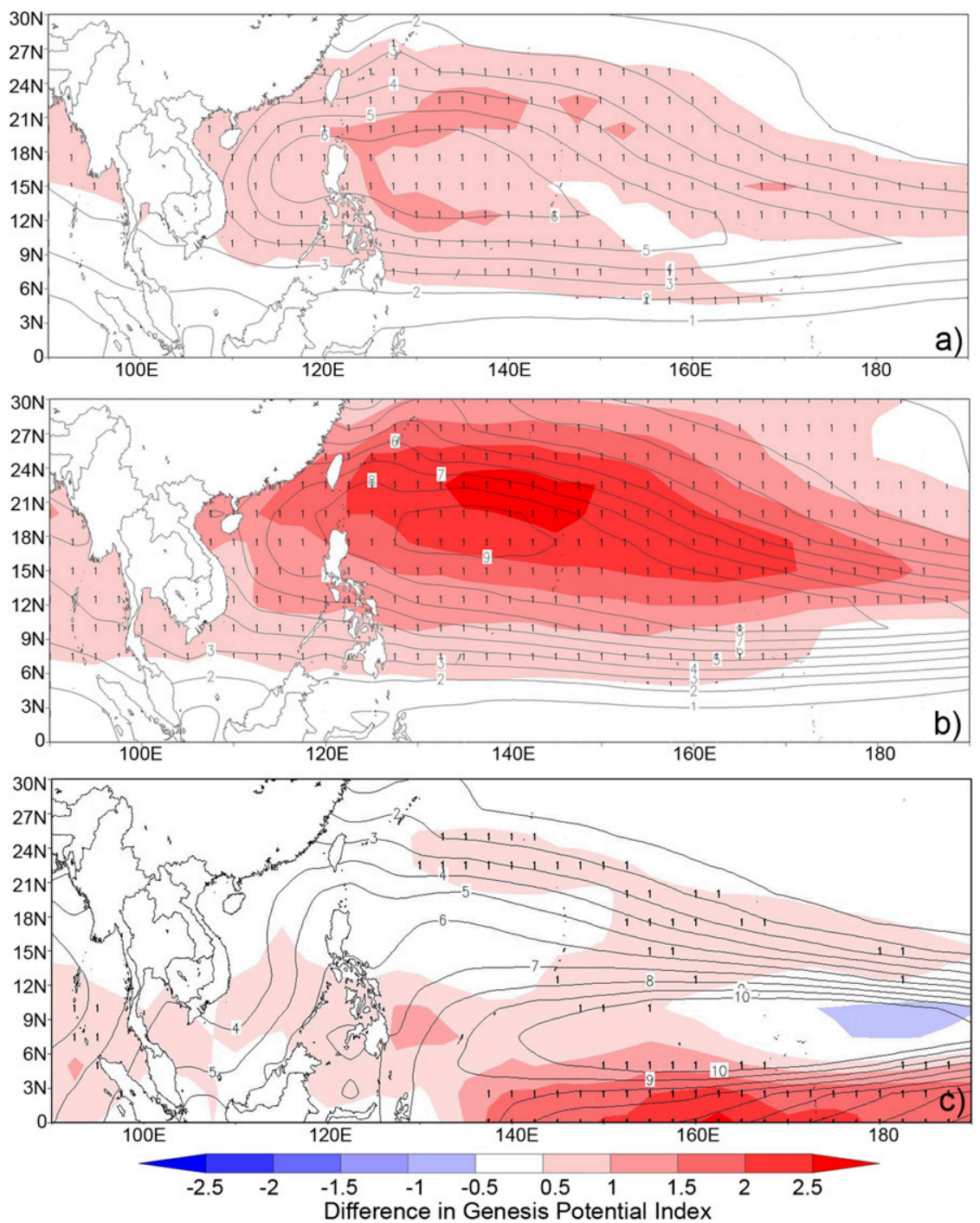

FIG. 10. The projected change in GPI between the first and last 20-yr average for (a) CMIP3

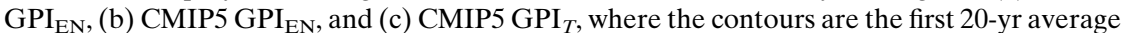
GPI respectively. The vertical dashes are where 12 or more of the CMIP3 models in (a) or 18 or more of the CMIP5 models in (b) and (c) agree on the sign of change.

where $\eta$ is the $850-\mathrm{mb}$ absolute vorticity (in $\mathrm{s}^{-1}$ ), $\mathcal{H}$ is the $700-\mathrm{mb}$ relative humidity $(\%), V_{\text {pot }}$ is the maximum potential intensity (MPI in $\mathrm{m} \mathrm{s}^{-1}$; Emanuel 1995), and $V_{\text {shear }}$ is the magnitude of the vertical wind shear be-

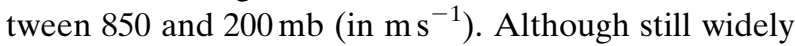
used, certain limitations to this index are addressed in Tippett et al. (2011) and an alternative GPI is proposed (referred to as $\mathrm{GPI}_{T}$ ) that is defined as

$$
\begin{aligned}
\mathrm{GPI}_{T}= & \exp \{-5.8+1.03[\min (\eta, 3.7)]+0.05 \mathcal{H} \\
& +0.56 T+0.15 \mathrm{~V}+\log \cos \phi\},
\end{aligned}
$$

where $\min (\eta, 3.7)$ is the clipped 850 -mb absolute vorticity (in $\left.10^{5} \mathrm{~s}^{-1}\right), \mathcal{H}$ is the 600 -mb relative humidity (\%),
$T$ is the relative SST (in ${ }^{\circ} \mathrm{C}$ ), and $V$ is the magnitude of the vertical wind shear between 850 and $200 \mathrm{mb}$ (in $\mathrm{m} \mathrm{s}^{-1}$ ); the values for the various constant multipliers are from line 6 of Table 1 in Tippett et al. (2011). The values are then multiplied by 40 as the coefficients were defined based on GPI frequency per $40 \mathrm{yr}$.

The CMIP3 experiment uses the same model produced GPI from Vecchi and Soden (2007) for each of the 17 models $\left(\mathrm{GPI}_{\mathrm{EN}}\right)$. For the CMIP5 experiment, both $\mathrm{GPI}_{\mathrm{EN}}$ and $\mathrm{GPI}_{T}$ are calculated for each of the 26 models. The seasonal (June-November) difference in GPI is calculated for the first $20 \mathrm{yr}$ and last $20 \mathrm{yr}$ and then averaged to form the ensemble mean. Following CSVK13, the storm count in each grid box of a given TC is weighted by 

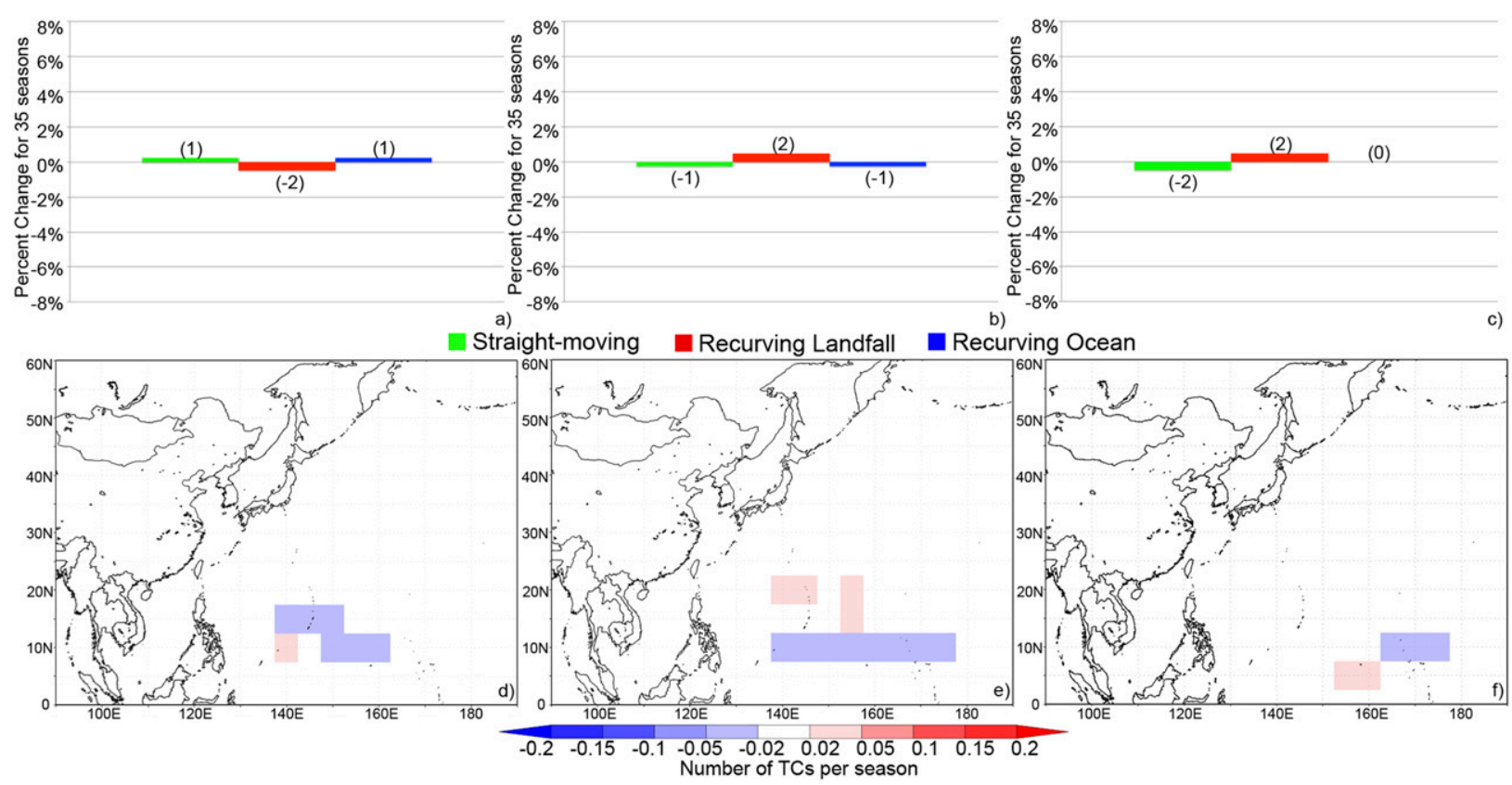

FIG. 11. (top) The projected changes in frequency of the three track types and (bottom) the spatial distribution of TC storm count due to changes in GPI only for (a),(d) the CMIP3 experiment weighted by GPI $\mathrm{EN}_{\mathrm{N}}$, and for the CMIP5 experiment weighted by (b),(e) GPI $\mathrm{EN}$ and (c),(f) $\mathrm{GPI}_{\mathrm{T}}$. The numbers in parentheses in (a)-(c) represent the change in the number of storms within each track category.

the GPI of the genesis location for that storm. As in CSVK13, the spatial distribution of model-simulated GPI is similar to that observed, so we do not anticipate a significant contribution from areas where TCs do not historically occur. Likewise, no attempt to account for changes in TC frequency, intensity, or size is included in this study, rather only changes in genesis location.

The methodology followed in this study permits us to isolate the contributions of changes in the large-scale steering flow and changes in genesis location to the change in TC tracks. A tracking algorithm could also be used to analyze projected changes in model produced TCs (e.g., Murakami et al. 2011; Yokoi et al. 2013). However, the complexity of the models makes it more difficult to unambiguously separate the contributions of multiple factors (e.g., changes in genesis location or steering flow) that contribute to the resulting changes in storm tracks. Additionally, our methodology only requires monthly temporal resolution of archived data, enabling a larger sample of climate model simulations to be considered from both CMIP3 and CMIP5 ensembles.

\section{a. Projected changes in TC tracks}

For each simulation the tracks are classified into the three categories (SM, RCL, and RCO) to analyze changes in frequency of the different track types. There is a significant decrease in SM TCs and increase in RCO TCs for both the CMIP3 and CMIP5 experiments (Figs. 9a-c). Little change is noted for RCL storms. The projected decreases of $\sim(4 \%-6 \%)$ in SM TCs and increases of $\sim(5 \%-7 \%)$ in RCO TCs are statistically significant at the $90 \%$ level based upon a two-tailed binomial test (see CS12). The pattern of more recurvature of TCs is similar to that found in the North Atlantic by CSVK13, suggesting a common mechanism underlies this response.

To further examine the projected changes in TC tracks, the difference in storm count is plotted for each experiment (Figs. 9d-f). In all three experiments, there is a decrease of $\sim(3-5)$ TCs per decade throughout the Philippines and South China Sea and an increase in the central WNP of $\sim(1-3)$ TCs per decade. There is also a slight increase near southern Japan, suggesting that the TCs systematically recurve more throughout the region. The spatial pattern of change in storm counts is similar in all three experiments.

To further understand the cause of these changes, we separate the contributions of steering flow and genesis location to the projected changes in TC storm distribution.

\section{b. Changes in genesis location}

To isolate the impact of changes in genesis location on the TC tracks, we examine the change in the CTRL track simulations (Fig. 6b) when weighted by the difference between the first and last 20-yr averaged GPI for each experiment. The change in GPI is shown in Fig. 10 for each experiment. All three experiments simulate 

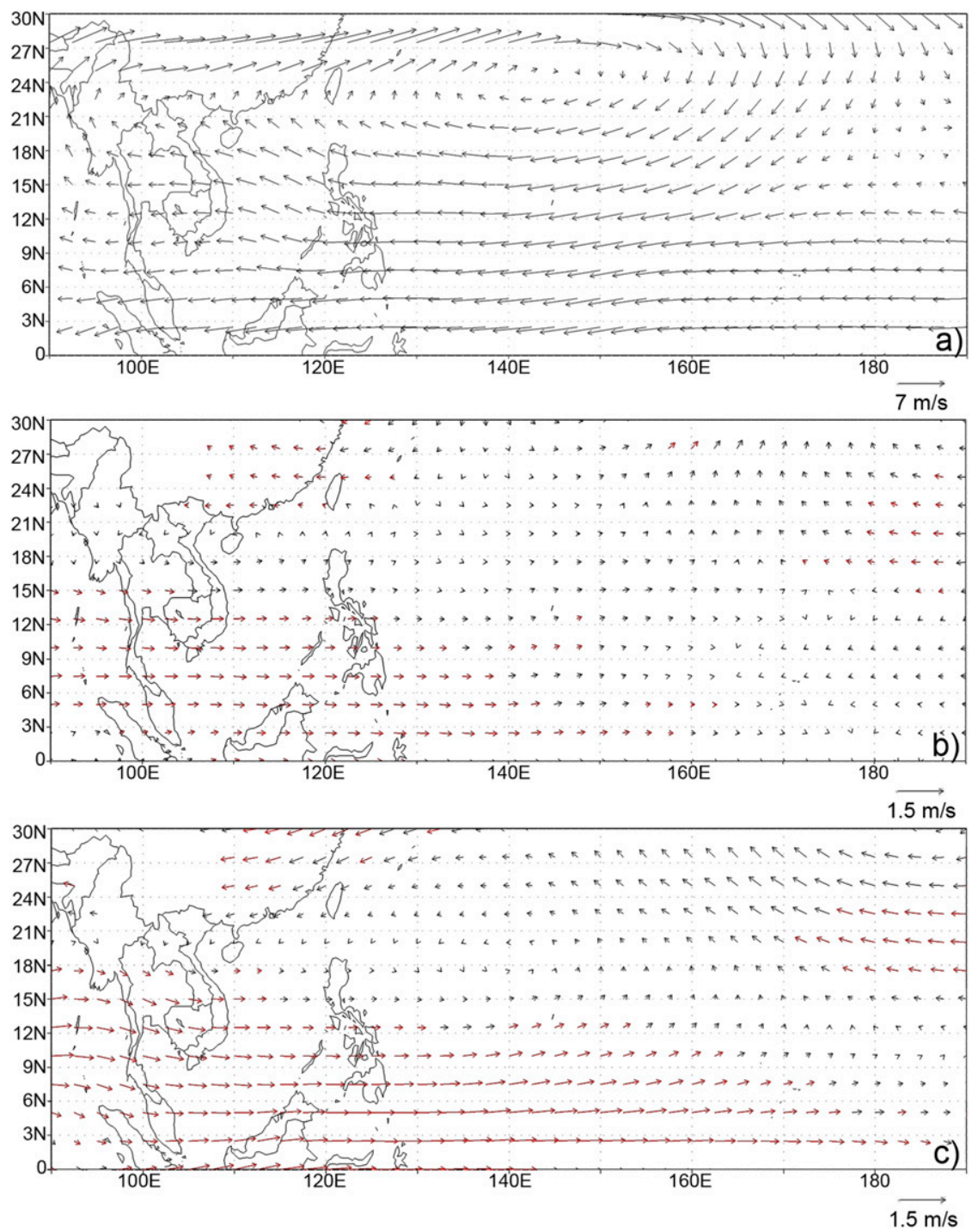

FIG. 12. (a) The corresponding NCEP-NCAR reanalysis deep-layer steering flow averaged over all MDR-forming TCs for their duration from 1976 to 2010. Also shown is the ensemble mean anomalous deep-layer steering flow difference averaged over all MDR-forming TCs for their duration for (b) CMIP3 [(2081-2100) - (2001-20)] and (c) CMIP5 [years (121-140) (years 1-20)]. The red arrows denote where 12 or more of the CMIP3 models in (b) and 18 or more of the CMIP5 models in (c) agree on the zonal sign of change.

increased GPI, although the pattern of increase differs notably between the $\mathrm{GPI}_{\mathrm{EN}}$ and $\mathrm{GPI}_{T}$ experiments. Because of the larger radiative forcing, the increase is greater in CMIP5 than CMIP3. However, even in CMIP5 the changes are small in comparison to the climatological average GPI (contours).

The resulting changes in the frequency of track types are small and not statistically significant (Figs. 11a-c). The difference in the spatial distribution of storm counts is also very small (Figs. 11d-f) relative to the simulations that consider both changes in GPI and large-scale steering flow. Thus, because the changes in GPI are small compared to the climatological mean, there is only a small contribution of a change in genesis location to the simulated changes in TC tracks.

\section{c. Changes in the large-scale steering flow}

To isolate the impact of changes in the large-scale steering flow, the BAM simulations using the CTRL winds are compared to those simulated using both CMIP3 and CMIP5 wind anomalies, but excluding the GPI weighting of the resulting TC tracks. Figure 12 shows the mean steering flow for the CTRL simulations and the projected change in the mean steering flow for both 

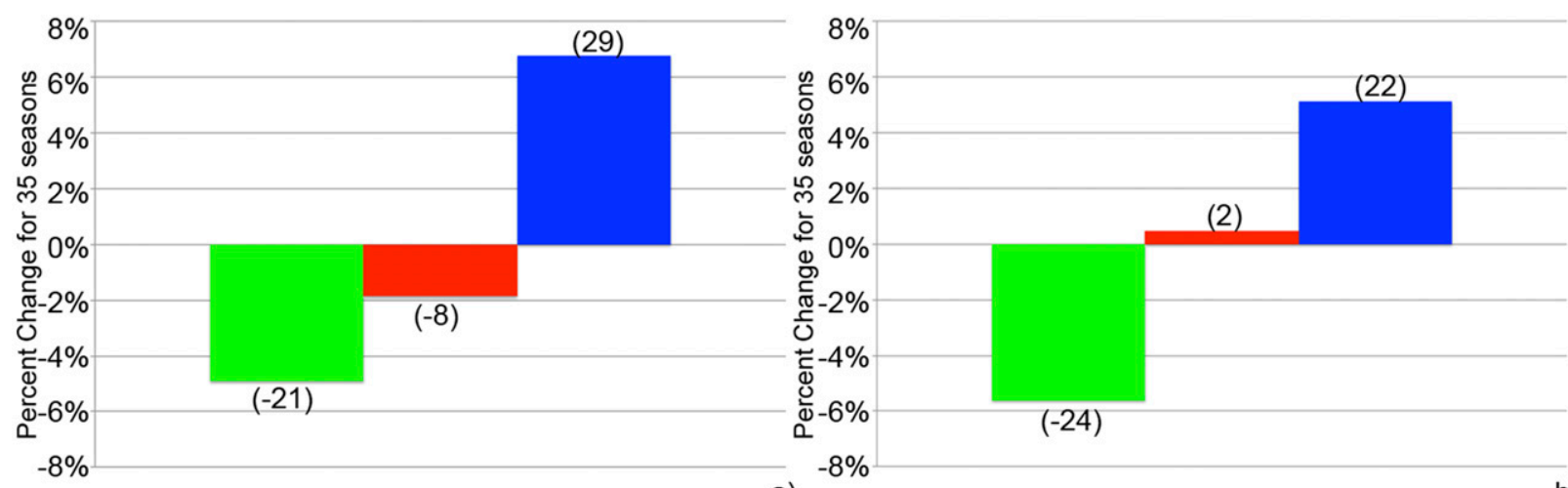

a)

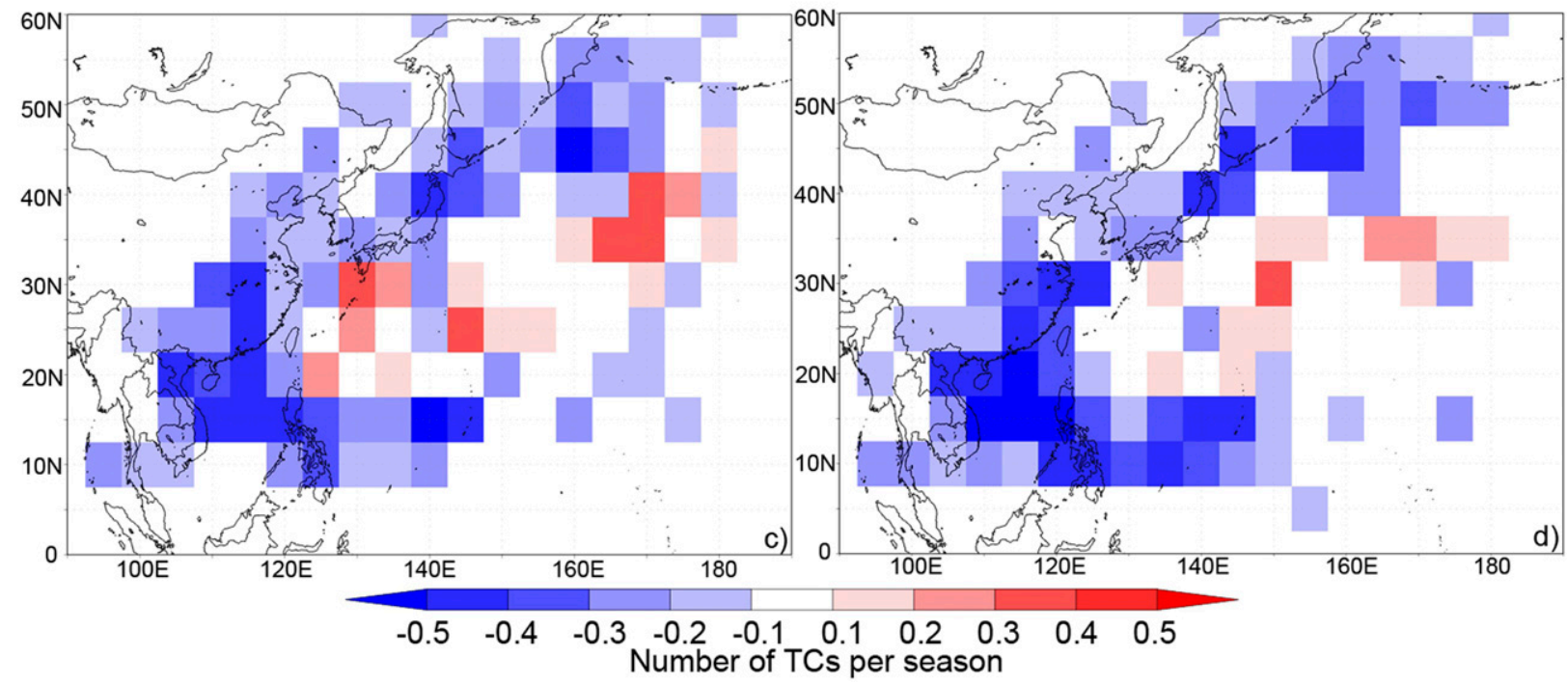

FIG. 13. (top) The projected changes in frequency of the three track types (colors as in Fig. 11) and (bottom) the spatial distribution of TC storm count due to changes in steering flow only for the (a),(c) CMIP3 and (b),(d) CMIP5 experiments. The numbers in parentheses in (a) and (b) represent the change in the number of storms within each track category.

CMIP3 and CMIP5. The average is computed only when a TC is present. The simulations result in a decrease in SM TCs of $\sim 5 \%$ and an increase of $\sim 6 \%$ in RCO TCs that are statistically significant at least for the $90 \%$ level (Figs. 13a,b). In terms of storm counts, these changes correspond to a decrease of $\sim(3-5)$ TCs per decade over the South China Sea and Philippines and an increase of $\sim(1-3)$ TCs per decade over the central WNP (Figs. 13c,d). The pattern of change is similar to that noted in Fig. 9, confirming that the primary contribution to the changes in TC tracks is from changes in the large-scale steering flow.

In both the CMIP3 and CMIP5 experiments, a weakening of the easterlies extends from the South China Sea across the Philippines and into the southern portion of the WNP. The slower easterlies allow more time for the $\beta$ drift to steer TCs northward, resulting in an increased likelihood of recurvature.
Because of the similarity of the results in the WNP to the results found in the North Atlantic (CSVK13), we examine the global change in the large-scale steering flow. Figure 14 shows the ensemble mean, global, zonal deep-layer steering flow, monthly averaged JuneNovember wind field for CMIP3 and CMIP5. The spatial distribution is very similar between the two experiments, with larger changes in the CMIP5 experiment due to the larger radiative forcing. Both experiments show a coherent reduction in the strength of the subtropical easterlies in both basins and both hemispheres, with larger reductions over the North Atlantic compared to the North Pacific. These wind anomalies are robust across models and correspond to a weakening of the mean tropical circulation in response to anthropogenic warming (Held and Soden 2006; Vecchi and Soden 2007). Taken together, the results of this study and CSVK13 argue that the weakening of the mean circulation may 

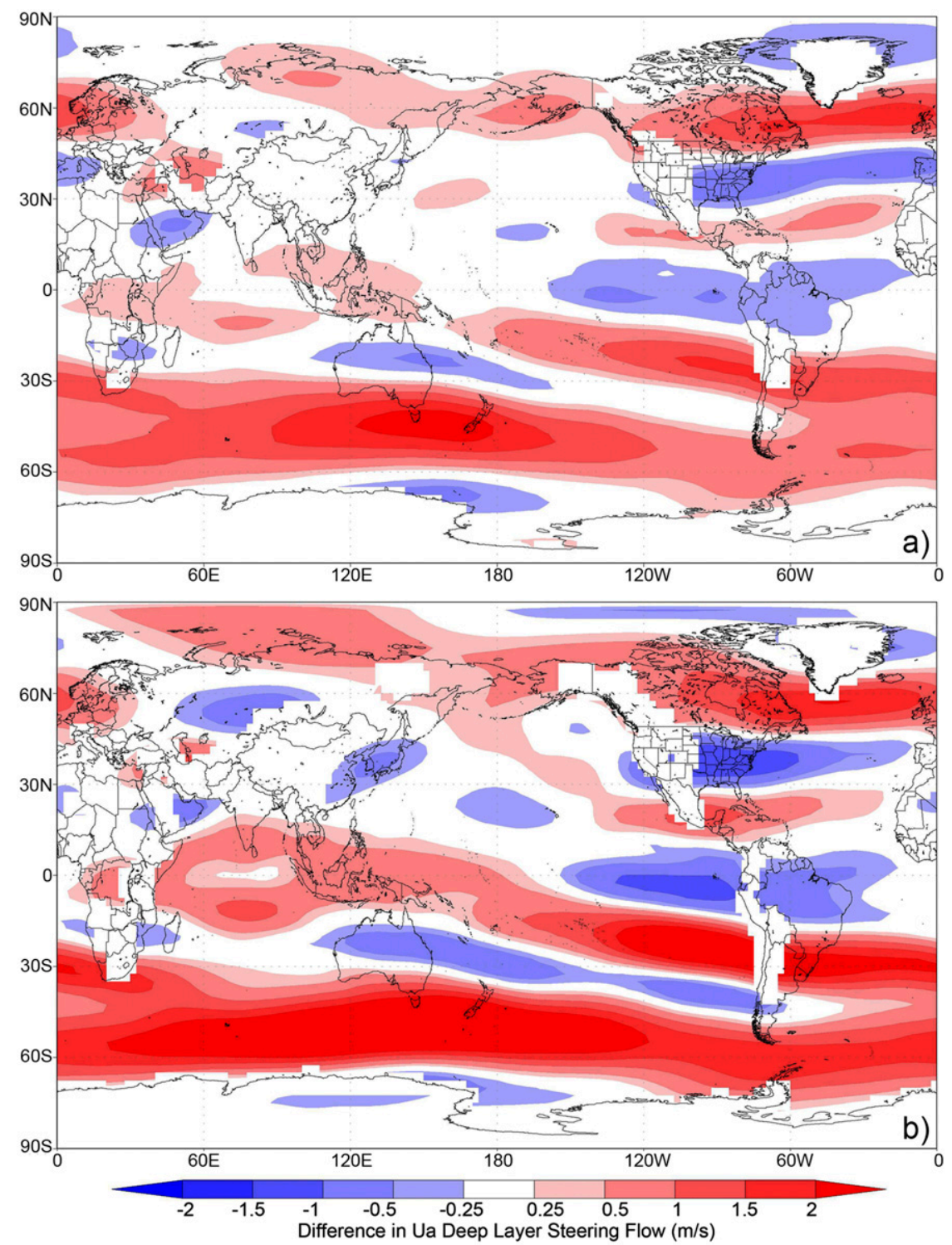

FIG. 14. The ensemble-mean change in the zonal component of the deep-layer steering flow averaged over June-November for (top) CMIP3 [(2081-2100) - (2001-20)] and (bottom) CMIP5 [(years 121-140) - (years 1-20)].

lead to fewer landfalling storms in both the North Pacific and North Atlantic basins due to a slowing of the easterly trade winds.

\section{Summary}

In this study, we examined the impact of natural and anthropogenic climate variability on WNP TC tracks. Natural climate variability provides a basis for assessing the sensitivity of this region's TC climatology to large-scale changes in climate and testing the ability of the BAM to reproduce observed shifts in TC tracks.
TCs that form in the MDR over the period 1976-2010 were classified into three track categories based on region of threat and simulations with a BAM were used to determine the importance of genesis location and largescale steering flow in determining the storm tracks. Similar to the North Atlantic (CS12), the tracks associated with RCL and RCO TCs are largely determined by differences in their large-scale steering flow, whereas SM TCs are primarily caused by their southward genesis location.

Next, we examined the impact of natural climate variability associated with ENSO, PDO, and IMR. Anomalously low SLP in the MDR was found to be associated with a steering flow that favors open ocean 
recurvature of TCs during El Niño. The uniform seeding experiments suggest that changes in the large-scale steering flow are primarily responsible for this shift, whereas changes in genesis location are important, as had previously been suggested (e.g., Sobel and Maloney 2000; Camargo et al. 2007), but contribute as a secondary enhancement to this shift in the average tracks. Little change in TC tracks was found to occur in response to variations in the PDO or IMR.

The BAM is then used to assess potential changes in TC tracks over the WNP due to anthropogenic climate change. Ensemble mean projections are composited from 17 CMIP3 models under the A1b scenario and 26 CMIP5 models under the $1 \%$ to doubling of $\mathrm{CO}_{2}$ scenario. The simulations result in a statistically significant decrease in SM TCs $[\sim(4 \%-6 \%)]$ and increase in RCO TCs $[\sim(5 \%-7 \%)]$. The track frequency shifts correspond spatially to a decrease of $\sim(3-5)$ TCs per decade in the Philippines and South China Sea and increase of $\sim(1-3)$ TCs per decade in the central WNP. These results are consistent with those found in previous studies ( $\mathrm{Wu}$ and Wang 2004; Murakami et al. 2011; Yokoi et al. 2013).

The projected changes in TC tracks under future warming scenarios are primarily caused by a reduction in the easterlies that slows the storm movement, allowing more time for the TC to drift northward and recurve. Similar results were found in the North Atlantic basin by CSVK13. These results suggest that a weakening of the mean atmospheric circulation in response to anthropogenic warming leads to fewer straight-moving storms and more recurving storms over the twenty-first century.

Acknowledgments. This research was partially supported by grants from the NOAA Climate Program Office and NASA. We also thank Gabriel Vecchi, Chris Landsea, and Amy Clement for their input with this study and the three reviewers for their valuable comments.

\section{REFERENCES}

Camargo, S. J., and A. H. Sobel, 2005: Western North Pacific tropical cyclone intensity and ENSO. J. Climate, 18, 29963006, doi:10.1175/JCLI3457.1.

_ K. A. Emanuel, and A. H. Sobel, 2007: Use of a genesis potential index to diagnose ENSO effects on tropical cyclone genesis. J. Climate, 20, 4819-4834, doi:10.1175/JCLI4282.1.

Chan, J. C. L., 2000: Tropical cyclone activity over the western North Pacific associated with El Niño and La Niña events. J. Climate, 13, 2960-2972, doi:10.1175/1520-0442(2000)013<2960: TCAOTW $>2.0$. CO 2 .

- 2008: Decadal variations of intense typhoon occurrence in the western North Pacific. Proc. Roy. Soc. London, 464A, 249-272, doi:10.1098/rspa.2007.0183.

Chen, T.-C., S.-Y. Wang, M.-C. Yen, and W. A. Gallus, 2004: Role of the monsoon gyre in the interannual variation of tropical cyclone formation over the western North Pacific. Wea. Forecasting, 19, 776-785, doi:10.1175/1520-0434(2004)019<0776: ROTMGI $>2.0 . \mathrm{CO} ; 2$.

,$- \ldots$, and $\_, 2006$ : Interannual variation of the tropical cyclone activity over the western North Pacific. J. Climate, 19, 5709-5720, doi:10.1175/JCLI3934.1.

Chia, H. H., and C. F. Ropelewski, 2002: The interannual variability in the genesis location of tropical cyclones in the northwest Pacific. J. Climate, 15, 2934-2944, doi:10.1175/ 1520-0442(2002)015<2934:TIVITG >2.0.CO;2.

Climate Prediction Center, cited 2011: Cold and warm episodes by season. [Available online at http://www.cpc.noaa.gov/products/ analysis_monitoring/ensostuff/ensoyears.shtml.]

Colbert, A. J., and B. J. Soden, 2012: Climatological variations in North Atlantic tropical cyclone tracks. J. Climate, 25, 657-673, doi:10.1175/JCLI-D-11-00034.1.

_ - - , G. A. Vecchi, and B. P. Kirtman, 2013: The impact of anthropogenic climate change on North Atlantic tropical cyclone tracks. J. Climate, 26, 4088-4095, doi:10.1175/ JCLI-D-12-00342.1.

Elsner, J. B., and K.-B. Liu, 2003: Examining the ENSO-typhoon hypothesis. Climate Res., 25, 43-54, doi:10.3354/cr025043.

Emanuel, K. A., 1995: Sensitivity of tropical cyclones to surface exchange coefficients and a revised steady-state model incorporating eye dynamics. J. Atmos. Sci., 52, 3969-3976, doi:10.1175/1520-0469(1995)052<3969:SOTCTS>2.0.CO;2.

— mate system. 26th Conf. on Hurricanes and Tropical Meteorology, Miami, FL, Amer. Meteor. Soc., 10A.2. [Available online at https://ams.confex.com/ams/26HURR/techprogram/ paper_75463.htm.]

Held, I. M., and B. J. Soden, 2006: Robust responses of the hydrological cycle to global warming. J. Climate, 19, 5686-5699, doi:10.1175/JCLI3990.1.

Ho, C., J. Baik, J. Kim, and D. Gong, 2004: Interdecadal changes in summertime typhoon tracks. J. Climate, 17, 1767-1776, doi:10.1175/1520-0442(2004)017<1767:ICISTT>2.0.CO;2.

Kalnay, E., and Coauthors, 1996: The NCEP/NCAR 40-Year Reanalysis Project. Bull. Amer. Meteor. Soc., 77, 437-471, doi:10.1175/1520-0477(1996)077<0437:TNYRP>2.0.CO;2.

Kim, H.-M., P. J. Webster, and J. A. Curry, 2011: Modulation of North Pacific tropical cyclone activity by three phases of ENSO. J. Climate, 24, 1839-1849, doi:10.1175/ 2010JCLI3939.1.

Knapp, K. R., M. C. Kruk, D. H. Levinson, H. J. Diamond, and C. J. Neumann, 2010: The International Best Track Archive for Climate Stewardship (IBTrACS): Unifying tropical cyclone best track data. Bull. Amer. Meteor. Soc., 91, 363-376, doi:10.1175/2009BAMS2755.1.

Knutson, T. R., and Coauthors, 2010: Tropical cyclones and climate change. Nat. Geosci., 3, 157-163, doi:10.1038/ngeo779.

Liu, K. S., and J. C. L. Chan, 2008: Interdecadal variability of western North Pacific tropical cyclone tracks. J. Climate, 21, 4464-4476, doi:10.1175/2008JCLI2207.1.

Mantua, N. J., S. R. Hare, Y. Zhang, J. M. Wallace, and R. C. Francis, 1997: A Pacific interdecadal climate oscillation with impacts on salmon production. Bull. Amer. Meteor. Soc., 78, 1069-1079, doi:10.1175/1520-0477(1997)078<1069: APICOW $>2.0 . C O ; 2$.

Molinari, J., and D. Vollaro, 2013: What percentage of western North Pacific tropical cyclones form within the monsoon trough? Mon. Wea. Rev., 141, 499-505, doi:10.1175/ MWR-D-12-00165.1. 
Murakami, H., B. Wang, and A. Kitoh, 2011: Future change of western North Pacific typhoons: Projections by a $20-\mathrm{km}-\mathrm{mesh}$ global atmospheric model. J. Climate, 24, 1154-1169, doi:10.1175/ 2010JCLI3723.1.

- , and Coauthors, 2012: Future changes in tropical cyclone activity projected by the new high-resolution MRI-AGCM. J. Climate, 25, 3237-3260, doi:10.1175/JCLI-D-11-00415.1.

Oouchi, K., J. Yoshimura, H. Yoshimura, R. Mizuta, S. Kusunoki, and A. Noda, 2006: Tropical cyclone climatology in a globalwarming climate as simulated in a $20 \mathrm{~km}$-mesh global atmospheric model: Frequency and wind intensity analyses. J. Meteor. Soc. Japan, 84, 259-276, doi:10.2151/jmsj.84.259.

Parthasarathy, B., A. A. Munot, and D. R. Kothawale, 1995: Monthly and seasonal rainfall series for all-India homogeneous regions and meteorological subdivisions: 1871-1994. Indian Institute of Tropical Meteorology Research Rep. RR-065, 114 pp.

Sikka, D. R., 1980: Some aspects of the large-scale fluctuations of summer monsoon rainfall over India in relation to fluctuations in the planetary and regional scale circulation parameters. Proc. Indian Acad. Sci., 89, 179-195.

Sobel, A. H., and E. D. Maloney, 2000: Effect of ENSO and the MJO on western North Pacific tropical cyclones. Geophys. Res. Lett., 27, 1739-1742, doi:10.1029/1999GL011043.

Stowasser, M., Y. Wang, and K. Hamilton, 2007: Tropical cyclone changes in the western North Pacific in a global warming scenario. J. Climate, 20, 2378-2396, doi:10.1175/JCLI4126.1.

Tao, L., L. Wu, Y. Wang, and J. Yang, 2012: Influences of tropical Indian Ocean warming and ENSO on tropical cyclone activity over the western North Pacific. J. Meteor. Soc. Japan, 90, 127144, doi:10.2151/jmsj.2012-107.

Tippett, M. K., S. J. Camargo, and A. H. Sobel, 2011: A Poisson regression index for tropical cyclone genesis and the role of large-scale vorticity in genesis. J. Climate, 24, 2335-2357, doi:10.1175/2010JCLI3811.1.

Vecchi, G. A., and B. J. Soden, 2007: Increased tropical Atlantic wind shear in model projections of global warming. Geophys. Res. Lett., 34, L08702, doi:10.1029/2006GL028905.
Wang, B., and J. C. L. Chan, 2002: How strong ENSO events affect tropical storm activity over the western North Pacific. J. Climate, 15, 1643-1658, doi:10.1175/1520-0442(2002)015<1643: HSEEAT $>2.0 . \mathrm{CO} ; 2$

Wang, C., and X. Wang, 2013: Classifying El Niño Modoki I and II by different impacts on rainfall in southern China and typhoon tracks. J. Climate, 26, 1322-1338, doi:10.1175/ JCLI-D-12-00107.1.

Wu, L., Z. Wen, R. Huang, and R. Wu, 2012: Possible linkage between the monsoon trough variability and the tropical cyclone activity over the western North Pacific. Mon. Wea. Rev., 140, 140-150, doi:10.1175/MWR-D-11-00078.1.

$\mathrm{Wu}$, L. G., and B. Wang, 2004: Assessing impacts of global warming on tropical cyclone tracks. J. Climate, 17, 1686-1698, doi:10.1175/1520-0442(2004)017<1686:AIOGWO>2.0.CO;2.

Wu, M. C., W. L. Chang, and W. M. Leung, 2004: Impacts of El Niño-Southern Oscillation events on tropical cyclone landfalling activity in the western North Pacific. J. Climate, 17, 1419-1428, doi:10.1175/1520-0442(2004)017<1419:IOENOE>2.0.CO;2.

Yokoi, S., Y. N. Takayabu, and H. Murakami, 2013: Attribution of projected future changes in tropical cyclone passage frequency over the western North Pacific. J. Climate, 26, 4096-4111, doi:10.1175/JCLI-D-12-00218.1.

Yonekura, E., and T. M. Hall, 2011: A statistical model of tropical cyclone tracks in the western North Pacific with ENSOdependent cyclogenesis. J. Appl. Meteor. Climatol., 50, 17251739, doi:10.1175/2011JAMC2617.1.

Yu, J.-H., Y. Wang, and K. Hamilton, 2010: Response of tropical cyclone potential intensity to a global warming scenario in the IPCC AR4 CGCMs. J. Climate, 23, 1354-1373, doi:10.1175/ 2009JCLI2843.1.

Yumoto, M., and T. Matsuura, 2001: Interdecadal variability of tropical cyclone activity in the western North Pacific. J. Meteor. Soc. Japan, 79, 23-35, doi:10.2151/jmsj.79.23.

Zhan, R., Y. Wang, and X.-T. Lei, 2011: Contributions of ENSO and east Indian Ocean SSTA to the interannual variability of northwest Pacific tropical cyclone frequency. J. Climate, 24, 509-521, doi:10.1175/2010JCLI3808.1. 